\title{
Ecophysiological responses to drought and salinity in the cosmopolitan invader Nicotiana glauca
}

\author{
Armando González' ${ }^{1}$, Wilmer Tezara ${ }^{1}$, Elizabeth Rengifo², Ana Herrera ${ }^{1 *}$
}

\begin{abstract}
${ }^{1}$ Centro de Botánica Tropical, Instituto de Biología Experimental, Facultad de Ciencias, Universidad Central de Venezuela, Caracas, Venezuela.
\end{abstract}

${ }^{2}$ Centro de Ecología, Instituto Venezolano de Investigaciones Científicas, Altos de Pipe, Venezuela.

ॠCorresponding author: ana.herrera@ciens.ucv.ve

Received: July 12 2012; Accepted: November 12012

\begin{abstract}
Nicotiana glauca, a shrub native to southern South America, is widely distributed in the Americas, from Patagonia to the USA, from zero up to $3,700 \mathrm{~m}$; it rapidly invades disturbed environments. In Venezuela, it has been reported from zero up to 2,000 m growing in contrasting conditions of relative humidity, temperature, rainfall, and salinity. In order to gain insight into the extent and mode of resistance to drought and salinity in $\mathrm{N}$. glauca, we studied the effect of these factors on water relations and photosynthesis under both natural and greenhouse conditions. In the field, water potential, photosynthetic rate (A) and stomatal conductance $\left(g_{s}\right)$, but not relative water content (RWC) decreased because of drought. Manual removal of epicuticular wax increased excess energy dissipation through non-photochemical quenching without altering the capacity of photochemical quenching. In the greenhouse, water deficit as well as salinity resulted in osmotic adjustment; at the end of the experiment, turgor potential and RWC under water deficit were similar to control and higher under salinity. Water deficit and salinity caused marked decreases in $A$ and $g_{s}$. There were very few or no changes with natural drought, salinity or experimental water deficit in potential quantum efficiency of PSII, which could be explained partly by an increased nonphotochemical quenching. We conclude that the partial tolerance to drought and salinity in plants of $N$. glauca resides in their ability to achieve water conservation through stomatal closure and osmotic adjustment, reduce absorption of excess radiation through the presence of leaf wax and dissipate it through increased non-photochemical quenching. All these characteristics confer plants of $\mathrm{N}$. glauca advantages to invade disturbed areas, subject to salinity and/or seasonal drought under high irradiance.
\end{abstract}

Keywords: drought, osmotic adjustment, salinity, water deficit.

\section{INTRODUCTION}

In arid ecosystems, water deficit is the main factor limiting $A$ and plant growth; only those species with mechanisms of drought resistance can prosper in waterlimited environments. Adaptation to water deficit, whether through avoidance or tolerance, involves reductions in cell dehydration. Some examples of avoidance are leaf shedding and reduction in stomatal conductance $\left(g_{s}\right)$; tolerance to water deficit usually implies the development of low osmotic potential $\left(\psi_{s}\right)$ through osmotic adjustment
(Lawlor and Tezara, 2009), which helps the maintenance of turgor potential $\left(\psi_{T}\right)$. However, as soil dries and at long term, plant water potential $(\psi)$ and RWC decrease, resulting in limitation to leaf gas exchange and, therefore, wholeplant growth and functioning (Lawlor and Tezara, 2009).

Since salinity is a common feature of arid and semiarid environments, plants have developed mechanisms to tolerate salinity as well as water deficit (Munns and Tester, 2008). Salinity often induces osmotic adjustment, which is considered as an important mechanism for the 
maintenance of water uptake and cell turgor under stress conditions (Chaves et al., 2008). One of the earlier and more marked effects of salinity on plant physiology is a reduction in $g_{s}$; later on, a reduction in $A$ often ensues.

Nicotiana glauca is a shrub native to southern South America, widely distributed in the Americas from Patagonia to the USA, from zero up to $3,700 \mathrm{~m}$; it rapidly invades tropical or subtropical disturbed environments. It has become a cosmopolitan plague invading, among other places, Australia (Florentine et al., 2006). In Venezuela, it has been reported from zero up to 2,000 m growing in contrasting conditions of relative humidity $(\mathrm{RH})$, temperature, rainfall, and salinity. Its growth is fast, probably due to a moderate high A (ca. $17 \mu \mathrm{mol} \mathrm{m}{ }^{-2} \mathrm{~s}^{-1}$; Medina, 1981). Its leaves are succulent and have a thick epicuticular waxy layer. Under severe water deficit, plants shed part or the totality of their leaves; eventually, plant dies (Florentine et al., 2006). In a survey of 60 species of the genus Nicotiana, relative growth rate of $N$. glauca decreased to $51 \%$ of control when $\mathrm{NaCl}$ concentration in the root medium was $150 \mathrm{mM}$, the authors placing this species among the salt-tolerant ones (Komori et al., 2000).

In arid environments, the effects of drought and salinity must be overcome in the presence of excess radiation, which may affect the function of the photosynthetic apparatus. The fraction of the incident solar radiation absorbed by the leaf is directly proportional to the leaf absorptance $(\alpha)$ in the 400-00 (photosynthetically active radiation, PAR) and the 400-3,000 nm (PAR+IR) wavelength bands (Ehleringer, 1981). The seasonal reduction in $\alpha$, from 0.81 to 0.29 , due to drought-induced increase in pubescence of Encelia farinosa, represents an adaptation to arid environments characterized by low water availability and high temperatures (Ehleringer, 1981). The presence of a waxy epicuticular layer on the leaves of some arid species must have implications on the leaf energy balance. We can expect the epicuticular waxy layer in leaves of $N$. glauca to reduce the absorption of excess heat under stress conditions.

Despite its invader habit, there is little information available on the ecophysiology of $N$. glauca and its response to water deficit or salinity. The knowledge of how plants of N. glauca respond to common stresses seems important to understand its invasive behavior. Florentine et al. (2006) have called attention to the need for ecological research on this species, which they consider to be a pest; also, the adaptations of seedlings of $N$. glauca to extreme environmental conditions add to other traits associated to the invader habit, such as high seed production.

In the central coast in Venezuela, where plants of N. glauca grow, drought, soil salinity and excess radiation surely affect the physiology of these plants. In order to gain insight into the degree and mode of resistance of N. glauca to water deficit, salinity and high irradiance, we followed the seasonal and experimental responses to water deficit and salinity of water relations and photosynthesis, measured through leaf gas exchange and chlorophyll a fluorescence. In addition, $\alpha$ and manual removal of leaf wax were estimated in order to evaluate the impact of wax on photochemical activity. We hypothesized that in plants of $N$. glauca, mechanisms of tolerance to water deficit, salinity and high irradiance, such as osmotic adjustment, increased succulence, stomatal closure and maintenance of photochemical activity under high irradiance operate, allowing plants to invade disturbed areas, subject to seasonal drought and/or salinity under high irradiance.

\section{MATERIAL AND METHODS}

Study area and plant material: Measurements were made in the field in Estado Vargas (10 $34^{\prime} \mathrm{N}, 67^{\circ} 9^{\prime} \mathrm{W}$ ) in plants of Nicotiana glauca R. Graham growing on sandy soil near the seaside, and in the greenhouse at Instituto de Biología Experimental, at $960 \mathrm{~m}$. Weather data were obtained from Instituto Nacional de Meteorología e Hidrología (INAMEH, Venezuela). Twelve individuals collected in the field were grown in the greenhouse in 8-L pots filled with commercial soil and watered every other day for one month before experiments. Plants $(n=4$ per treatment) were subjected to three treatments: frequent watering (control), cessation for 20 days of watering of pots at field capacity (water deficit) and watering of plants every other day for 20 days with $170 \mathrm{mM} \mathrm{NaCl}$ (approximately $30 \%$ seawater concentration in the Caribbean; salinity). Soil water potential was measured psychrometrically as described below, in sections of $5-\mathrm{cm}^{3}$ soil cores taken at a depth of $5 \mathrm{~cm}$ after 20 days of treatment.

Microclimatic variables and salinity: Daily courses were conducted in the field (three in March-April 2007 and three in August-September 2008) of the following microclimatic variables: photosynthetic photon flux density (PFD) with a quantum sensor mod. 250-S (LI-COR Inc., Lincoln, NE); air and leaf temperature with a mod. 840210 telethermometer connected to three thermistors $\mathrm{N}^{\circ} 405$ and six thermistors $\mathrm{N}^{\circ} 409 \mathrm{~B}$, respectively (Cole-Parmer Instrument Company, Chicago, IL), and RH with a mod. $\mathrm{N}^{\circ}$ 3310-20 hygrometer (Cole-Parmer Instrument Company, Chicago, IL). Thermistors were attached to the abaxial face of the leaf using plastic paper clips, endeavoring to maintain the natural leaf angle. In the greenhouse, air temperature and $\mathrm{RH}$ were registered with two $\mathrm{HOBO}$ Pro 
V2 loggers and data were dumped with a HOBO Waterproof Shuttle (Onset Computer Corporation, Pocasset, MA); results presented are mean $\pm \mathrm{SE}$ of measurements of both loggers made during two consecutive days.

Plant water status: The water potential $(\psi)$ was measured in the field in 10 leaves at 6:00 am with a pressure chamber (PMS, Corvalis, OR) and in the greenhouse at 7:00 pm in one leaf disk, each of the four different plants were placed in C-52 chambers and were connected to the HR33T microvoltmeter (Wescor Inc., Logan, UT) operated in the dew-point mode; chambers were calibrated with $\mathrm{KCl}$ solutions of known osmolality (Wescor Inc., Logan, UT). The $\psi_{s}$ was determined likewise in the same leaf disks, frozen and measured immediately after removal from liquid nitrogen. Turgor potential was calculated as $\psi_{T}=\psi-\psi_{s}$. Leaf water content (LWC) was determined as leaf water mass on an area basis and RWC was the fraction of turgid mass after re-hydration in the dark for three hours at $4^{\circ} \mathrm{C}$ in disks of leaves collected in the field, enclosed in polythene bags with wet paper towels and transported to the laboratory over ice, and in leaf disks taken in the greenhouse and weighed at 7:00 am. Fresh and dry $\left(48 \mathrm{~h}\right.$ at $\left.60^{\circ} \mathrm{C}\right)$ masses of disks were weighed in an analytical balance (Adventurer, Ohaus, China). At the end of the experiment, pots were rewatered at 6:00 pm to field capacity and plants plus pot enclosed in a black polythene bag; $\psi_{s}$ at saturation $\left(\psi_{s}^{100}\right)$ was determined at 6:00 am the next day as aforementioned. Osmotic adjustment was calculated as $D \psi_{s}=\psi_{s}{ }_{s}^{100}{ }_{\text {control }}-\psi_{s}{ }^{100}$ treatment $^{\circ}$

Leaf gas exchange and chlorophyll a fluorescence: Daily courses of leaf gas exchange and chlorophyll a fluorescence (three per sampling date) were conducted. Leaf gas exchange was measured in youngest fully expanded leaves at $380 \mu \mathrm{mol}$ $\mathrm{CO}_{2} \mathrm{~mol}^{-1}, 21 \% \mathrm{O}_{2}, 30 \pm 3^{\circ} \mathrm{C}$ and, unless otherwise stated, a PFD of $1,500 \pm 100 \mu \mathrm{mol} \mathrm{m} \mathrm{m}^{-2} \mathrm{~s}^{-1}$. Two portable IRGAs were used, one mod. LCA-4 (Analytical Development Co., Hoddesdon, UK) in the field and, another mod. CIRAS 2 equipped with a chlorophyll a fluorescence module (PP Systems, Hitchin, UK) in the greenhouse. Previous measurements determined that values obtained with both systems on opposite leaves at the same time were not significantly different. In the field, the assimilation chamber received natural illumination; fluorescence was measured in leaves dark-adapted for 2 h using a fluorometer mod. PAM 2100 (Walz, Effeltrich, Germany). Fluorescence parameters, determined after Genty et al. (1989), were: maximum fluorescence in dark-adapted leaves $\left(F_{\mathrm{M}}\right)$ after a saturating pulse of $6,000 \mu \mathrm{mol} \mathrm{m} \mathrm{m}^{-2} \mathrm{~s}^{-1}$; effective quantum yield of $P S I I, \Phi_{P S||}=\left(F_{M}^{\prime}-F_{S}\right) / F_{M}$, in which $F_{\mathrm{s}}$ is steady-state fluorescence, maximum fluorescence in the light $\left(\mathrm{F}_{\mathrm{M}}\right)$; non-photochemical quenching $N P Q=\left(\mathrm{F}_{\mathrm{M}}-\mathrm{F}_{\mathrm{M}}\right)$ / $\mathrm{F}_{\mathrm{M}}$; and electron transport rate through PSII, $\mathrm{J}=\mathrm{PFD} \times \alpha \times$ $\Phi_{\text {PSII } ~} 0.5$ using values of $\alpha$ of watered plants in the $400-700$ $\mathrm{nm}$ band. The $\mathrm{J}$ was calculated by dividing data output of the fluorometers by the default $\alpha=0.85$ and multiplying data by the value of the actually determined $\alpha$. Fluorescence data shown in the greenhouse are PFD-saturated values obtained from light curves. Intrinsic water use efficiency was calculated as WUE = $\mathrm{A} / \mathrm{g}_{\mathrm{s}}$. Measurements of chlorophyll a fluorescence were made in both intact leaves and leaves from which wax was removed from the upper cuticle by gently rubbing it with the fingers. The complete removal of waxy layers was assessed in free-hand sections observed under the microscope. In the greenhouse, light curves ( $n=3$ per treatment) of leaf gas exchange and chlorophyll a fluorescence were performed between 8 and $12 \mathrm{~h}$, and PFD-saturated values were averaged for the three highest values of PFD. The $\alpha$ of intact and dewaxed leaves was measured with an integrating sphere mod. 1800-12 (LI-COR, Lincoln, NE). Leaf absorptance in the $400-3000 \mathrm{~nm}$ range was estimated in both intact and dewaxed leaves using the equation provided by Ehleringer (1981).

Leaf thickness and anatomy: In the field, whole-leaf thickness was measured with a vernier caliper $(n=20)$. In the greenhouse, one youngest fully expanded leaf per plant and treatment $(n=4)$ was fixed in $70 \% \mathrm{v} / \mathrm{v}$ ethanol and four mid-lamina free-hand sections per leaf cleared with $10 \%$ $\mathrm{v} / \mathrm{v}$ commercial bleach and stained with aqueous toluidine blue. Tissue thickness was measured in one section per slide with a binocular microscope (Leica DMLS, Sweden).

Chlorophyll content: Chlorophyll from two disks per leaf of four different individuals was extracted in cold $80 \%$ acetone in the dark, and chlorophyll concentration was measured with a mod. Spectronic 401 spectrophotometer (Milton Roy, Pennsylvania) and calculated after Bruinsma (1963).

Statistics: Values are mean \pm SE. Significance of differences $(p<0.05)$ was assessed through ANOVA and Duncan's multiple range test after assessment of variance normality, using the Statistica 5.5 package.

\section{RESULTS}

The field site is characterized by strong rainfall seasonality, with a well-defined dry season from January until March and a rainy season that lasts the rest of the year (Figure 1). Daily courses of air temperature, RH and PFD in the field, as well as the greenhouse and leaf temperature, are shown in Figure 2. In the field, large fluctuations in PFD during August-September (rainy season) showed a higher cloudiness than in March-April (dry season); no significant differences due to season in $\mathrm{RH}$ were found. At either season, leaf temperature was very similar to air temperature, with 
lower values between 12 and $14 \mathrm{~h}$ during the dry season; values of mean maximum air temperature for 14 years were $28.7 \pm 0.4$ (dry season) and $30.7 \pm 0.4^{\circ} \mathrm{C}$ (rainy season). At the hours of highest PFD (10-14 h), temperature of intact leaves was significantly lower than that of dewaxed leaves: $35.8 \pm 0.4$ and $37.2 \pm 0.5^{\circ} \mathrm{C}$, respectively. Conditions in the greenhouse were similar to those in the field at any season, except for significantly lower air temperatures.

The $\psi$ decreased 1.6 times with drought, while LWC was $16 \%$ higher under drought than during the rainy season; RWC showed no significant differences between seasons (Figure 3). Leaf thickness was $515 \pm 49$ and $761 \pm 22 \mu \mathrm{m}$ during the rainy and the dry season, respectively.

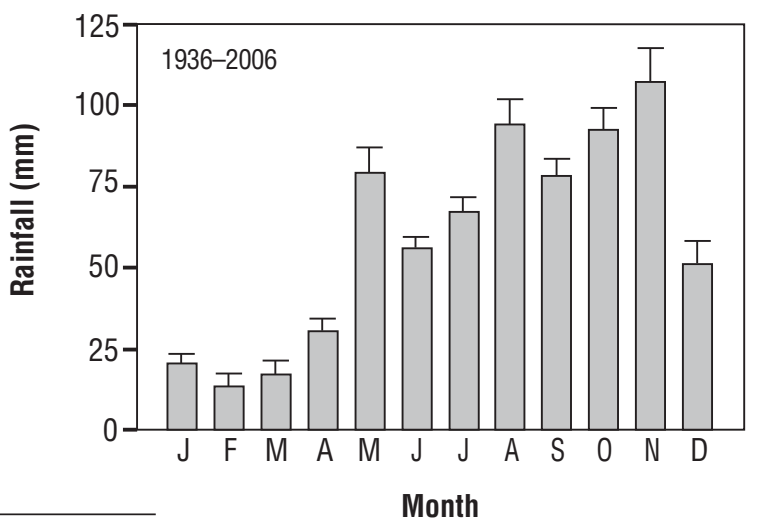

Figure 1. Rainfall in the study area. Values (mean \pm SE) were collected in seven weather stations around the sampling area from 1936-2006.

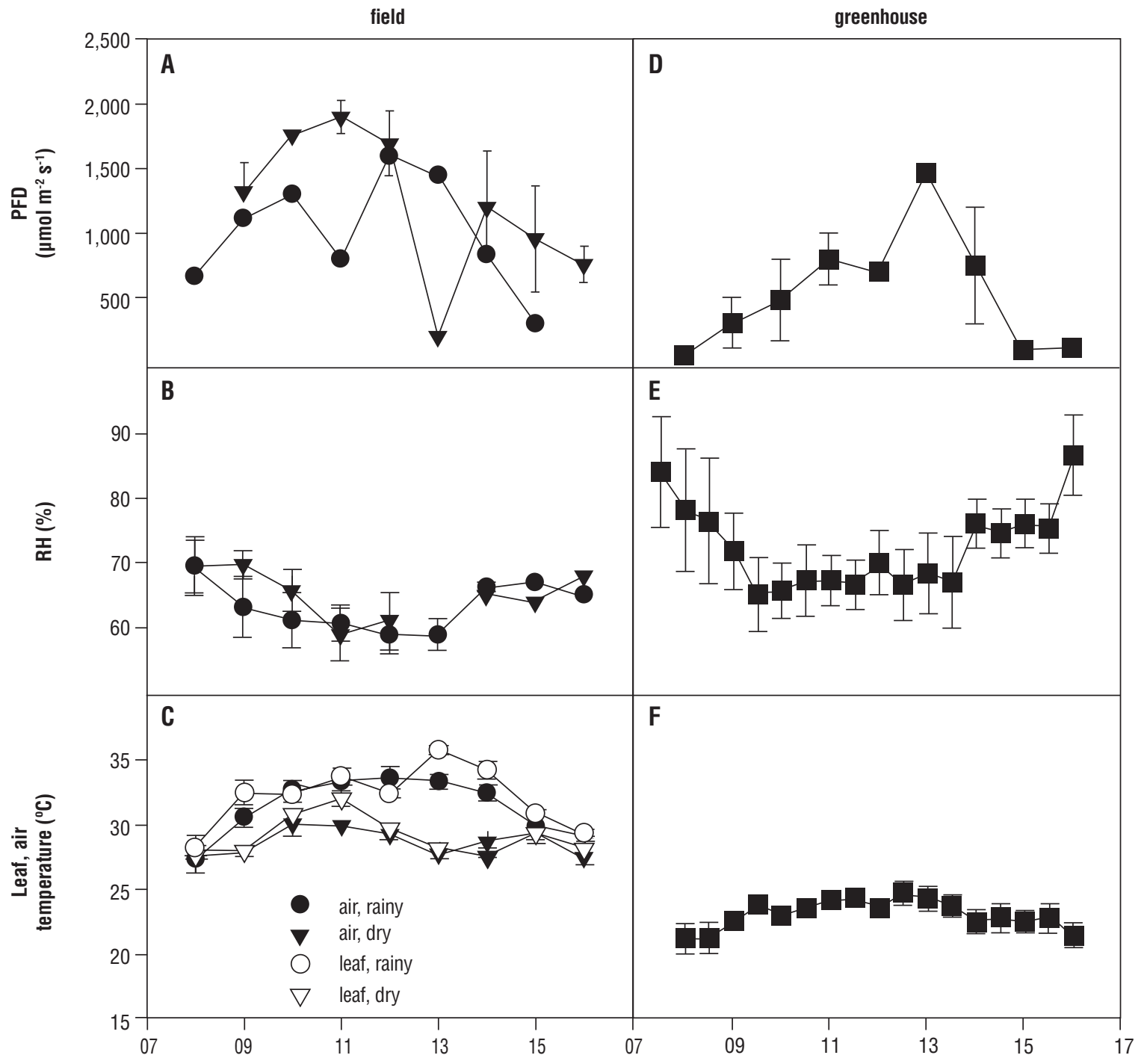

Figure 2. Daily courses in the field and in the greenhouse of: $(A, D)$ photosynthetic photon flux density; (B,E) relative humidity; (C) air and leaf temperature in the field; $(F)$ air temperature in the greenhouse. Circles and triangles, rainy and dry season; squares, greenhouse; closed symbols, air; open symbols, leaf. Values are mean $\pm \mathrm{SE}$ ( $\mathrm{n}=3$ for PFD, 6 for $\mathrm{RH}$ in the field, 4 for air temperature and $\mathrm{RH}$ in the greenhouse, 9 for temperature in the field and 4 for temperature in the greenhouse). 


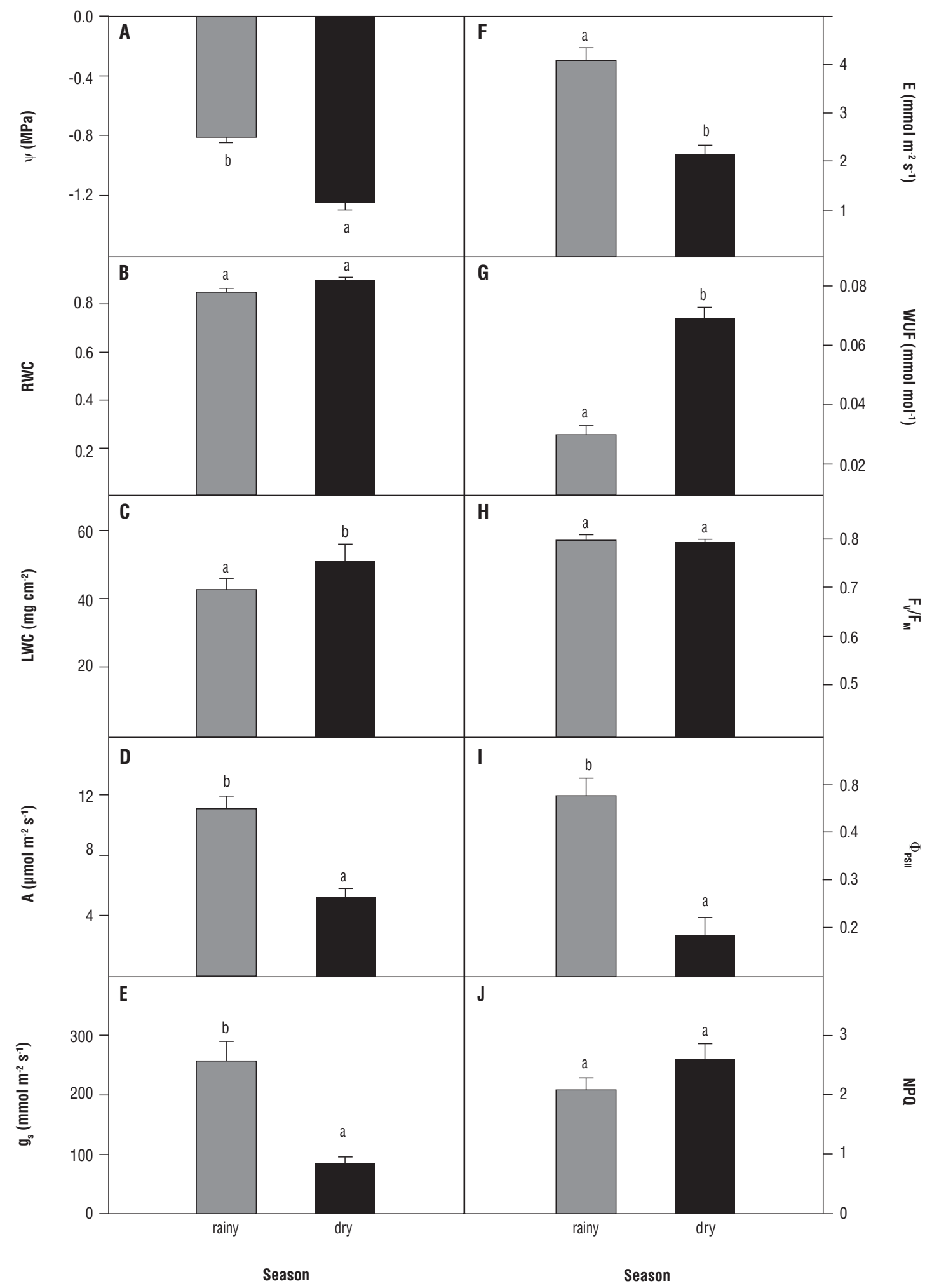

Figure 3. Seasonal changes in the field in: (A) water potential; (B), relative water content; (C), leaf water content; (D), photosynthetic rate; (E) stomatal conductance; (F), transpiration rate; $(\mathrm{G})$, water use efficiency; $(\mathrm{H})$, potential quantum yield of PSII; (I), effective quantum yield of PSII; (J), non-photochemical quenching coefficient. Values of leaf gas exchange, $\Phi_{\mathrm{PSII}}$ and NPQ are light-saturated. Values are mean $\pm \mathrm{SE}$ $(n=10)$. Different letters indicate significant differences at $p<0.05$. 
Values of $A, g_{s}$, E and the effective quantum yield of PSII $\left(\Phi_{\mathrm{PSII}}\right)$ during the rainy season were 2.2, 3.2, 1.9, 2.3 and 4.6 times higher, respectively, than at drought, whereas WUE was 2.3 times as high during the dry season, $F_{v} / F_{M}$ and non-photochemical quenching (NPQ), showing no effect of drought (Figure 3). From light curves done in situ (not shown), it was found that during the rainy season $\mathrm{J}$ became PFD-saturated at $790 \mu \mathrm{mol} \mathrm{m}{ }^{-2} \mathrm{~s}^{-1}$ PFD.

The $\alpha$ was $0.81 \pm 0.1$ and $0.72 \pm 0.1$ in intact and dewaxed leaves, respectively, $\alpha v \delta$ significant differences occurred due to treatment. Intact leaves absorbed $41 \%$ of the incident radiation in the $400-3,000 \mathrm{~nm}$ range, whereas dewaxed leaves absorbed $48 \%$. During the dry season, no significant differences under similar PFD due to wax removal were found in either $\Phi_{\text {PSII }}$ or J, suggesting lack of damage to PSII, while NPQ was 1.5 times as high in dewaxed than in intact leaves (Figure 4). Leaves that had been dewaxed were not used for further measurements during the daily courses, since gas exchange became severely impaired compared to intact leaves (results not shown), probably due to dehydration.

The time-course of changes in the greenhouse in water relations, gas exchange and chlorophyll fluorescence variables are shown in Figure 5 . The $\psi$ and $\psi_{\mathrm{s}}$ diminished significantly due to water deficit and salinity, but $\psi_{\mathrm{T}}$, RWC and LWC at the end of the experiment were similar (water deficit) or higher (salinity) than in control, suggesting the occurrence of osmotic adjustment. Osmotic adjustment determined in resaturated plants was $-2.58 \pm 0.66$ and $-3.77 \pm 0.47 \mathrm{MPa}$ under salinity and water deficit, respectively. The LWC was $100 \%$ of the control under water deficit and $150 \%$ under salinity. In spite of increased succulence, leaf sap osmolality calculated on a LWC basis and assuming that $\mathrm{NaCl}$ was the osmolite responsible for $D \psi_{s}{ }^{100}$ was 1.8 times higher under salinity than in control. Soil water potential after 20 days was $-0.16 \pm 0.09 \mathrm{MPa}$ in the control, $-2.5 \pm 0.5$ $\mathrm{MPa}$ in the water deficit treatment and $-3.06 \pm 0.36 \mathrm{MPa}$ in the salinity treatment.

At the end of the experiment, neither total chlorophyll content nor chlorophyll a:b ratio showed significant differences due to treatment during the entire experiment; mean ratio values with data from both treatments were $1.6 \pm 0.1$ chlorophyll $\mathrm{a} / \mathrm{b}$. Under water deficit and salinity, $A$ and $g_{\mathrm{S}}$ were lower, while WUE, $\Phi_{\mathrm{PSI}}$ and NPQ were higher than in control. A small (5\%) but significant decrease in $\mathrm{F}_{\mathrm{V}} / \mathrm{F}_{\mathrm{M}}$ relative to day 0 was found in all three treatments, probably due to acclimation to greenhouse conditions, but there were no significant differences between treatments

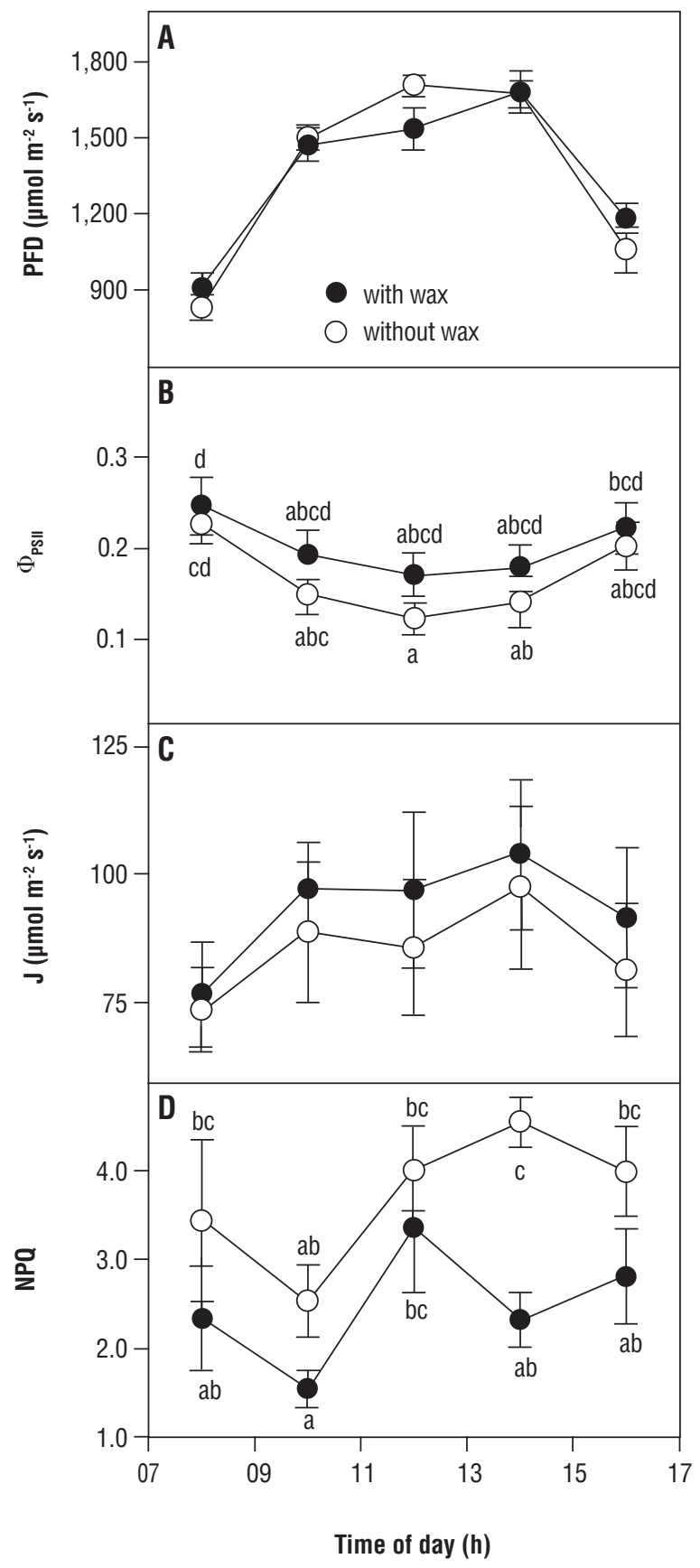

Figure 4. Daily changes during the dry season in the field in: (A) photosynthetic photon flux density; (B) effective quantum yield of PSII; (C) electron transport rate; (D) non-photochemical quenching coefficient of plants of Nicotiana glauca with (closed symbols) or without (open symbols) leaf wax. Values are mean \pm SE $(n-6)$. Different letters indicate significant differences at $p<0.05$ after a two-way ANOVA (treatment $x$ hour of day).

at the end of the experiment. The effect of salinity on physiological variables was more marked than that of water deficit. 


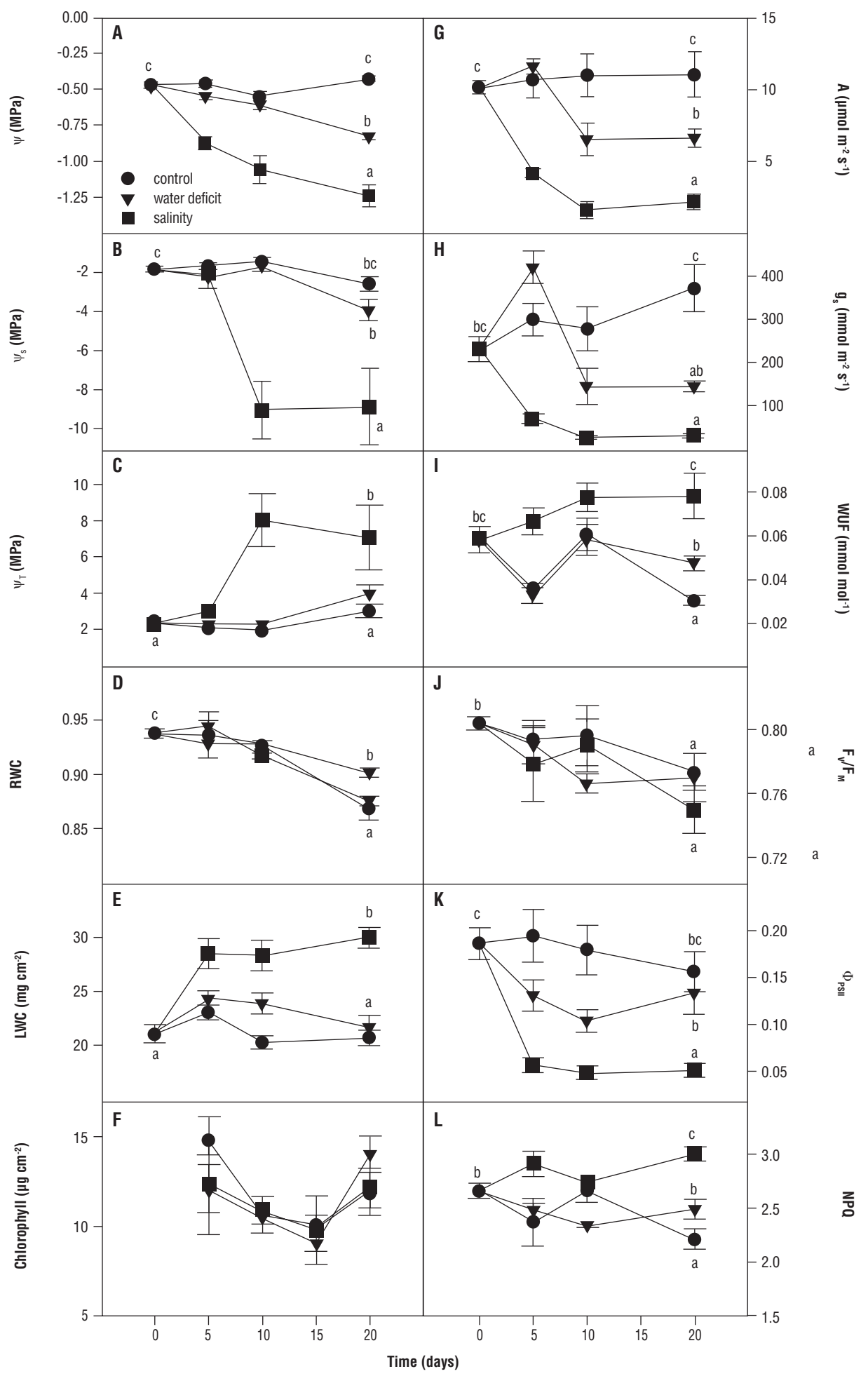

Figure 5. Changes with time under treatment of plants of Nicotiana glauca subjected to frequent watering (circles), water deficit (triangles) or salinity (squares) in the greenhouse in: (A) water potential; (B) osmotic potential; (C) turgor potential; (D) relative water content; (E) leaf water content; (F) total chlorophyll content; (G) photosynthetic rate; (H) stomatal conductance; (I) water use efficiency; (J) potential quantum yield; (K) effective quantum yield; (L) non-photochemical quenching coefficient. Values of leaf gas exchange, $\Phi_{P S I I}$ and NPQ are light-saturated. Values are mean $\pm S E(n=4)$. Different letters indicate significant differences at $p<0.05$ determined after a two-way ANOVA (time $x$ treatment, 0 and 20 days). 
An approximate $20 \%$ leaf shedding took place before the end of the experiment under salinity, but not under water deficit, denoting only partial tolerance to salinity.

No significant changes in tissue thickness were found due to water deficit, whereas salinity caused a significant thickening of the spongy parenchyma after 20 days (Figure 6), which resulted in a $34 \%$ increase in whole-leaf thickness $(401 \pm 7 \mu \mathrm{m}$ under salinity vs. $304 \pm 10 \mu \mathrm{m}$ in control).

\section{DISCUSSION}

Responses of water relations, leaf exchange and chlorophyll a fluorescence variables in plants of $\mathrm{N}$. glauca to water deficit and salinity were similar between the field and the greenhouse, in spite of marked differences in air temperature and soil salinity.

Values of $A$ in the field and in the greenhouse were similar to those reported by Medina (1981) and Funk and Zachary (2010). Marked decrease in gas exchange and some of the fluorescence parameters was found between seasons in the field and under water deficit and salinity in the greenhouse. Similarly, a decrease in $A$ and $E$ of approximately 66 and 33\%, respectively, was observed in plants of $N$. glauca subjected to water deficit for seven days (Funk and Zachary, 2010). The decrease in A occurred at high water status $(-1.20$ and $-1.05 \mathrm{MPa}$ in the field and in the greenhouse, respectively). In the sympatric xerophytes Ipomoea carnea and Jatropha gossypifolia, A was nearly zero at $\Psi=-2 \mathrm{MPa}$, in contrast to the drought-tolerant species Alternanthera crucis, in which A became zero only when $\Psi$ was lower than -8 MPa (Tezara et al., 1998).

During both seasons, especially during the dry one, when leaf overheating could be expected because of lower $g_{s}$ and evaporative cooling, leaf temperature in N. glauca closely followed air temperature. These results suggest an important role for epicuticular wax in decreasing $\alpha$ and preventing leaf overheating. In intact leaves of $N$. glauca, $\alpha$ was lower than in glabrous, non-glaucous leaves, in which $\alpha=0.85$ (Ehleringer 1981). A value of $\alpha=0.83$ has been reported for plants of $N$. glauca growing in the Mojave and Sonora deserts (Ehleringer 1981); the discrepancy between our value and that reported by the latter could be because the plants studied by him grew under conditions of higher water supply. Intact leaves of $N$. glauca absorb $7 \%$ less incident radiation in the 400-3,000 $\mathrm{nm}$ range than dewaxed leaves; thus, the reduction in absorption in this range due to epicuticular wax must have a significant impact on leaf

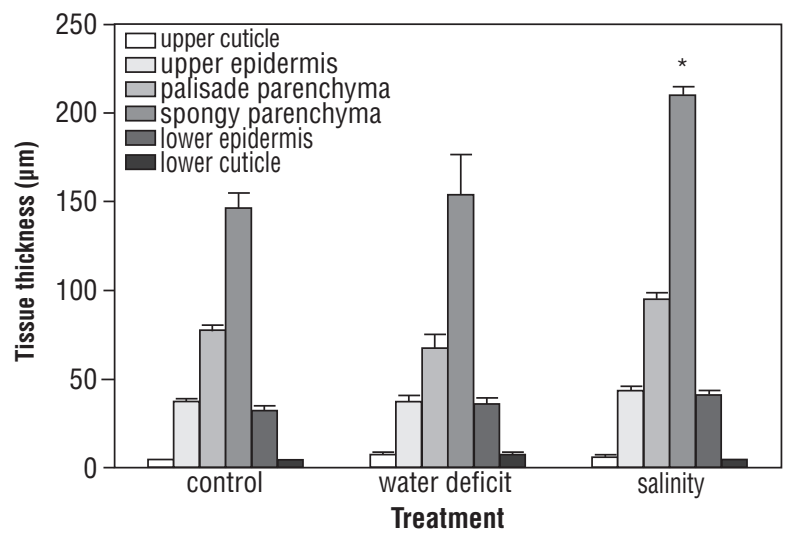

Figure 6. Changes with treatment in leaf tissue thickness of plants of Nicotiana glauca subjected to frequent watering, water deficit or salinity in the greenhouse. Measurements were made after 20 days of treatment. The subtitle for tissues is enclosed. Values are mean $\pm \mathrm{SE}(\mathrm{n}=4)$. An asterisk indicates significant differences at $p<0.05$ among treatments for spongy parenchyma.

overheating; besides, dewaxed leaves measured in the field at the time of maximum PFD were significantly warmer than intact leaves. A photoprotective mechanism was inferred from measurements of chlorophyll a fluorescence in d-waxed leaves, whereby NPQ almost doubled without changes in $\Phi_{\text {PSII }}$. This mechanism could reside in the presence of a large xanthophyll pool capable of dissipating excess energy.

Plants of $N$. glauca showed partial tolerance to water deficit and salinity, since $\Psi_{T}$ remained similar to (water deficit) or higher (salinity) than the control due to the occurrence of osmotic adjustment. Osmotic adjustment was higher under salinity than under water deficit, $\Psi_{\mathrm{s}}$ of plants under salinity being far lower than that in the soil. Osmotic adjustment is commonly seen in halophytes, in which it occurs through salt absorption that, in turn, causes an increase in succulence (Flowers and Colmer, 2008), similarly to that found in plants of N. glauca subjected to salinity.

The effects of salinity on physiological responses of $N$. glauca during the dry season in the field could be even more evident than in our experimental design, since plants in the field would suffer from the combined effects of soil salinity and drought. A strong stomatal closure was found in both the field and in the greenhouse, which increased WUE in the field but not in the water deficit treatment in the greenhouse, thus suggesting an effect of the combined water deficit and salinity in the increased WUE in the field. The higher osmotic adjustment achieved by plants of $\mathrm{N}$. glauca under salinity could assist for a better tolerance towards 
water deficit during the dry season in the field. When the combined effect of water deficit and salinity was experimentally examined in plants of Ipomoea pescaprae, using polyethylene glycol in order to reduce substrate $\Psi_{\mathrm{s}}$ (Sucre and Suárez, 2011), plants resulted more susceptible to water deficit than to soil salinity, while the water and carbon balances were even enhanced when both stresses were applied simultaneously.

In the greenhouse, a significant increase with salinity in whole-leaf and spongy parenchyma thickness was similar to that found in the halophyte Jaumea carnosa (St. Omer and Schlesinger, 1980). In this study, no significant differences due to treatment were found in cuticle thickness, in contrast to plants of $N$. glauca subjected to repeated cycles of water deficit, in which deposition of epicuticular wax increased 2.5 times (Cameron et al., 2006). In the present investigation, such increase may have been unnoticed because of the low resolution at which tissue thickness was measured, or because only one water deficit cycle was done.

An increase in $\Psi_{T}$ due to osmotic adjustment apparently did not aid in the improvement of the negative effects of salt on leaf gas exchange, as both water deficit and salinity caused decrease in A and $g_{s}$. In contrast, A remained constant for 15 days of salinity treatment with an osmotic adjustment of $0.94 \mathrm{MPa}$ in Lycium nodosum (Tezara et al., 2003).

Although $\mathrm{F}_{\mathrm{PSII}}$ decreased under salinity, the lack of difference with control in $F_{v} / F_{M}$ indicated that the photochemical apparatus is resistant to this factor. In the halophyte, $S$. salsa, $F_{V} / F_{M}$ remained unaffected by an increase in $\mathrm{NaCl}$ concentration, from 100 to $400 \mathrm{mM}$ (Lu et al., 2003). Under natural drought, as well as experimental water deficit and salinity, there is increase in NPQ of $N$. glauca compensated for the decrease in $\Phi_{\text {PSII }}$, which suggested down-regulation of photochemical activity. In sunflowers, water deficit produced a decrease in $\Phi_{\text {PSII }}$ without changes in $\mathrm{F}_{\mathrm{v}} / \mathrm{F}_{\mathrm{M}}$, suggesting the occurrence of down-regulation of the photochemical apparatus without chronic photoinhibition (Tezara et al., 2008). Maintenance of chlorophyll content in the greenhouse accompanied the near lack of change with season or treatment in $\mathrm{F}_{\mathrm{v}} /$ $\mathrm{F}_{\mathrm{M}}$, coinciding with observations in plants of $L$. nodosum, in which $F_{V} / F_{M}$ remained constant under water deficit and salinity (Tezara et al., 2003);

The partial tolerance of $N$. glauca to water deficit and salinity under conditions of high irradiance was confirmed according to determinations of the responses to these stresses of water relations, leaf gas exchange and chlorophyll a fluorescence. This tolerance may confer advantages to invade disturbed areas, subject to salinity and/or seasonal drought. Tolerance appeared to reside in: 1) the ability to effect osmotic adjustment, which, in the case of salinity, probably occurred through salt accumulation; 2) stomatal closure preventing excess leaf water loss, and 3 ) a reduction in absorbed energy and an efficient non-photochemical dissipation of the excess.

Acknowledgements: We acknowledge the kind help in the field from Gabriela Pereira, Oranys Marín and Valentina Villalobos. Rosa Urich and Nathalie Suárez did very thorough revisions of the manuscript.

\section{REFERENCES}

Bruuinsma J (1963) The quantitative analysis of chlorophylls $a$ and $b$ in plant extracts. Photochem. Photobiol. 2:241-249.

Cameron KD, Teece MA, Smart LB (2006) Increased accumulation of cuticular wax and expression of lipid transfer protein in response to periodic drying events in leaves of tree tobacco. Plant Physiol. 140:176-183.

Chaves MM, Flexas J, Pinheiro C (2009) Photosynthesis under drought and salt stress: regulation mechanisms from whole plant to cell. Ann. Bot. 103:551-560.

Ehleringer J (1981) Leaf absorptances of Mohave and Sonoran desert plants. Oecologia 49:366-370.

Florentine SK, Westbrooke ME, Gosney K, Ambrose G, O'Keefe M (2006) The arid land invasive weed Nicotiana glauca R. Graham (Solanaceae): population and soil seed bank dynamics, seed germination patterns and seedling response to flood and drought. J. Arid Environ. 66:218-230.

Funk JL, Zachary VA (2010) Physiological responses to short-term water and light stress in native and invasive plant species in southern California. Biol. Invasions 12:1685-1694.

Flowers TJ, Colmer TD (2008) Salinity tolerance in halophytes. New Phytol. 179:945-963.

Genty B, Briantais JM, Baker NR (1989) The relationship between the quantum yield of photosynthetic electron transport and quenching of chlorophyll fluorescence. Biochim. Biophys. Acta 990:87-92.

Komori T, Myers PN, Yamada S, Kubo T, Imaseki H (2000) Comparative studies of the Nicotiana species with respect to water deficit tolerance during early growth. Euphytica 116:121-130.

Lawlor DW, Tezara W (2009) Causes of decreased photosynthetic rate and metabolic capacity in water-deficient leaf cells: a critical evaluation of mechanisms and integration of processes. Ann. Bot. 103:561-579.

Lu C, Qiu N, Wang B, Zhang J (2003) Salinity treatment shows no effects on photosystem II photochemistry, but increases the resistance of photosystem II to heat stress in halophyte Suaeda salsa. J. Exp. Bot. 54:851-860.

Medina E (1981) Nitrogen content, leaf structure and photosynthesis in higher plants. A report to the United Nations Environmental Program study on Photosynthesis and Bioproductivity, Instituto Venezolano de Investigaciones Científicas, Caracas, Venezuela. 
Munns R, Tester M (2008) Mechanism of salinity tolerance. Annu. Rev. Plant Biol. 59:651-681.

St Omer L, Schlesinger WH (1980) Regulation of NaCl in Jaumea carnosa (Asteraceae), a salt marsh species, and its effect on leaf succulence. Am. J. Bot. 67:1448-1454

Sucre B, Suárez N (2011) Effect of salinity and PEG-induced water stress on water status, gas exchange, solute accumulation, and leaf growth in Ipomoea pes-caprae. Environ. Exp. Bot. 70:192-203.
Tezara W, Fernández MD, Donoso C, Herrera A (1998) Seasonal changes in photosynthesis and stomatal conductance of five plant species from a semiarid ecosystem. Photosynthetica 35:399-410.

Tezara W, Martínez D, Rengifo E, Herrera A (2003) Photosynthetic responses of the tropical spiny shrub Lycium nodosum (Solanaceae) to drought, soil salinity and saline spray. Ann. Bot. 92:757-765.

Tezara W, Driscoll S, Lawlor DW (2008) Partitioning of photosynthetic electron flow between $\mathrm{CO}_{2}$ assimilation and $\mathrm{O}_{2}$ reduction in sunflower plants under water deficit. Photosynthetica 46:127-134. 